\title{
Respiratory and intramuscular immunization with ChAdOx2 NPM1-NA induces distinct immune responses in H1N1pdm09 pre-exposed pigs
}

Eleni Vatzia ( $\nabla$ eleni.vatzia@pirbright.ac.uk)

The Pirbright Institute

Elizabeth Allen

University of Oxford https://orcid.org/0000-0002-6406-4834

Tanuja Manjegowda

The Pirbright Institute

\section{Susan Morris}

The Jenner Institute, University of Oxford

\section{Adam McNee}

Pirbright Institute

Veronica Martini

Pirbright Institute https://orcid.org/0000-0002-6086-0358

\section{Reshma Kaliath}

The Jenner Institute, University of Oxford

\section{Marta Ulaszewska}

University of Oxford

\section{Amy Boyd}

The Jenner Institute, University of Oxford

\section{Basu Pauday}

Pirbright Institute

\section{B Veronica Carr}

The Pirbright Institute

\section{Tiphany Chrun}

Pirbright Institute

\section{Emmanuel Maze}

Pirbright Institute

\section{Ronan MacLoughlin}

Aerogen https://orcid.org/0000-0002-3164-1607

\section{Pauline van Diemen}

$$
\text { APHA-Weybridge }
$$

Helen Everett 
APHA-Weybridge

Teresa Lambe

University of Oxford https://orcid.org/0000-0001-7711-897X

\section{Sarah Gilbert}

University of Oxford https://orcid.org/0000-0002-6823-9750

\section{Elma Tchilian}

Pirbright Institute https://orcid.org/0000-0002-4869-5118

\section{Article}

Keywords: Influenza A, pig, vaccine, pre-exposure, pdmH1N1, aerosol, intranasal, intramuscular Posted Date: August 11th, 2021

DOl: https://doi.org/10.21203/rs.3.rs-789957/v1

License: (c) (i) This work is licensed under a Creative Commons Attribution 4.0 International License. Read Full License 
Respiratory and intramuscular immunization with ChAdOx2 NPM1-NA induces distinct immune responses in $\mathrm{H} 1 \mathrm{~N} 1 \mathrm{pdm} 09$ pre-exposed pigs

Eleni Vatzia ${ }^{*}$, Elizabeth R. Allen ${ }^{2}$, Tanuja Manjegowda ${ }^{1}$, Susan Morris ${ }^{2}$, Adam McNee ${ }^{1}$, Veronica Martini ${ }^{1}$, Reshma Kaliath², Marta Ulaszewska ${ }^{2}$, Amy $^{2}$ Boyd $^{2}$, Basu Paudyal ${ }^{1}$, B Veronica Carr ${ }^{1}$, Tiphany Chrun ${ }^{1}$, Emmanuel Maze ${ }^{1}$, Ronan MacLoughlin ${ }^{3}$, Pauline M. van Diemen $^{4}$, Helen E. Everett ${ }^{4}$, Teresa Lambe ${ }^{2 \dagger}$, Sarah C Gilbert ${ }^{2 \dagger}$, Elma Tchilian ${ }^{1} \dagger^{\star}$

† equal contribution

*correspondence: Eleni Vatzia (eleni.vatziai@pirbright.ac.uk) and Elma Tchilian (elma.tchilian@pirbright.ac.uk)

${ }^{1}$ The Pirbright Institute, Pirbright, UK

${ }^{2}$ Nuffield Department of Medicine, The Jenner Institute, University of Oxford, Oxford, UK ${ }^{3}$ Aerogen Ltd, Galway, Ireland

${ }^{4}$ APHA-Weybridge, New Haw, Addlestone, United Kingdom

\section{Keywords}

Influenza A, pig, vaccine, pre-exposure, pdmH1N1, aerosol, intranasal, intramuscular 


\section{Abstract}

There is a critical need to develop superior influenza vaccines that provide broader protection. Influenza vaccines are traditionally tested in naïve animals, although humans are exposed to influenza in the first years of their lives, but the impact of prior influenza exposure on vaccine induced immune responses has not been well studied. Pigs are an important natural host for influenza, are a source of pandemic viruses, and are an excellent model for human influenza. Here we investigated the immunogenicity of the ChAdOx2 viral vectored vaccine, expressing influenza nucleoprotein, matrix protein 1 and neuraminidase in $\mathrm{H} 1 \mathrm{~N} 1 \mathrm{pdm} 09$ pre-exposed pigs. We evaluated the importance of route of administration by comparing intra-nasal, aerosol and intra-muscular immunizations. Aerosol delivery boosted the local lung $\mathrm{T}$ cell and antibody responses, while intra-muscular immunization boosted systemic immunity. These results will inform how best to deliver vaccines in order to harness optimal protective immunity.

\section{Introduction}

Influenza virus infection remains a global health threat to humans and animal influenza A virus is an important zoonotic pathogen with pandemic potential. There is an urgent need to develop vaccines that provide broader protection and decrease the need of annual vaccination. Resolution of two major issues should make rational immunization design easier. The first is that most humans or animals have already encountered influenza virus, and this may bias subsequent immune responses towards the virus epitopes from the first exposure (original antigenic sin) which may decrease vaccine induced protection 1,2 . Therefore, the immunological impact of prior influenza virus exposure on vaccine efficacy needs to be taken into account. The second is that although local immune responses are critical for protection against mucosal infection, whether local immunization offers a real advantage remains to be proven. 
Most people are infected with influenza viruses once every five years and this preexisting immunity can significantly impact vaccine efficacy ${ }^{3,4}$. Cross-reactive immunity acquired by prior seasonal influenza infections is due to T cell responses to conserved internal antigens and antibodies to conserved epitopes of the haemmaglutinin (HA) and neuraminidase (NA). It is well established that $T$ cell responses to conserved influenza $A$ proteins such as the nucleoprotein (NP) and matrix protein 1 (M1) acquired by infection with influenza virus offer protection against symptomatic disease upon re-infection ${ }^{5,6,7,8}$. We previously demonstrated that these T cell immune responses can be boosted by intramuscular immunization with replication defficient viral vectors Chimpanzee Adenovirus Oxford (ChAdOx) and Modified Vaccinia virus Ankara (MVA) expressing NP and M1 in humans ${ }^{9}$. We further showed that inclusion of a third antigen, the HA, in ChAdOx-NPM1-HA and MVANPM1-HA significantly reduced virus shedding in pigs after prime boost vaccination against homologous $\mathrm{H} 1 \mathrm{~N} 1 \mathrm{pdm} 09$ virus challenge ${ }^{10}$. Recent research has underlined the role of antiNA antibodies, which are induced after natural influenza virus infection ${ }^{11,12}$. Current vaccine development focuses on the HA where the majority of neutralizing epitopes are found. However, neutralizing antibodies (nAbs) directed to the HA are often on regions that have high sequence diversity and thus may not generate cross protection. Therefore the inclusion of NA as a component of the influenza vaccine may help provide robust and broad protection.

The route of immunization and induction of local immune response are critical for vaccine efficacy ${ }^{13,14,15}$. Although it is clear that local respiratory immune responses and tissue resident memory $T$ cells (TRM) are best induced by local respiratory immunization or infection, it is not clear which part of the respiratory tract (RT) should be targeted for optimal protection. Two airway immunization strategies have been developed: local nasal spray and aerosol delivery targeting the lung. In humans, an aerosol measles vaccine has been successfully deployed in Mexico and a live attenuated influenza virus (LAIV) is given to children and adults as a nasal spray ${ }^{16,17}$. Aerosolized vaccines are also currently investigated for COVID-19 ${ }^{18}$.

However, targeting the lower or upper respiratory tract (LRT or URT) has important safety and immunological implications ${ }^{19,20}$ and studies with measles ${ }^{21}$, Mycoplasma pulmonis 
${ }^{22}$, tuberculosis ${ }^{23}$, and influenza ${ }^{24,25,26,27}$ indicate that nasal delivery and lung targeting elicit distinct immune responses. In contrast, parenteral intramuscular delivery induces a systemic response, although there are reports showing that antigen specific $T$ cell may traffic to the mucosal surfaces after parenteral immunization ${ }^{28,29}$.

Based on these considerations, it is critical to study how vaccines can be optimally delivered to the different areas of the respiratory tract (RT) in large animal models and humans and to consider the effect of prior virus exposure on immune responses to the vaccine. Pigs, like humans, are a natural host for influenza A virus and display similar clinical manifestations and pathogenesis, making them an excellent large animal model for studying influenza infection and new vaccine candidates ${ }^{30}$. The lobar and bronchial anatomy of the pig lung is similar to that of humans, they share the same histological structure, epithelial lining, distribution of sialic acid receptors, and electrolyte transport ${ }^{31}$. We have developed methods to target different parts of the RT and used scintigraphy in vivo to analyse the distribution of antigen in pigs ${ }^{32}$. Furthermore, for the first time we have identified porcine TRM and characterised their specificity, function and distribution in the respiratory tract ${ }^{33,34,35}$.

Here we used these tools and the pig influenza virus model to determine how to target antigen delivery optimally to the respiratory tract to induce URT and LRT immunity. We evaluated the immunogenicity of ChAdOx2 expressing NP, M1 and NA after different routes of immunization: targeting the whole RT by aerosol, the URT intranasally or systemic immunity by intramuscular immunization in $\mathrm{H} 1 \mathrm{~N} 1$ pdm09 pre-exposed pigs.

\section{Results}

\section{Experimental design, virus shedding and antibody responses.}

We first considered the implications of generating a viral vectored vaccine expressing both the NA and the NPM1 fusion protein. We tested the immunogenicity of three ChAdOx2 vaccines in mice (ChAdOx2-NA, ChAdOx2-NPM1, and ChAdOx2 NPM1-NA). Mice were intramuscularly immunized with $8 \times 10^{7} \mathrm{IU} / \mathrm{ml}$ of $\mathrm{ChAdO} 2$ and euthanized three weeks later. T cell responses to NPM1 were measured by IFNy ELISpot and antibody responses to NA were 
measured by NA-ELISA. We found there were no significant differences in immune responses when comparing the bivalent vaccine construct ChAdOx2 NPM1-NA to the single antigen vaccines (Suppl. Fig. 1). Thanks to the strong immune responses generated with the bivalent vaccine we tested it in the context of influenza pre-exposure in a large natural host model.

In order to assess the effect of influenza pre-exposure on vaccine immune responses, twenty pigs were infected intranasally with $7.8 \times 10^{6} \mathrm{TCID}_{50}$ of $\mathrm{H} 1 \mathrm{~N} 1$ A/swine/England/1353/2009 (pH1N1) (Fig. 1a). Virus load after pH1N1 challenge was determined in daily nasal swabs (Fig. 1a). In agreement with previous studies virus load was detectable for 4 days post infection (DPI) followed by a sharp decline and was not detectable after $6 \mathrm{DPI}{ }^{35}$.

Four weeks after the $\mathrm{pH} 1 \mathrm{~N} 1$ exposure the pigs were divided into four groups of five animals and immunized with $5 \times 10^{8} \mathrm{IU}$ of ChAdOx2 virus vector expressing NPM1 and NA (ChAdOx2-NPM1-NA). The NP and M1 proteins derived from $\mathrm{H} 1 \mathrm{~N} 1$ A/swine/England/1353/2009 with GenBank accession numbers KR701098 and KR701100 respectively, while the NA from H3N2 A/swine/Ohio/A01354299/2017 with GenBank accession number MF801571. To evaluate the efficacy of parenteral and respiratory routes of immunization ChAdOx2-NPM1-NA was administered intra-muscularly (IM), by aerosol (AE) in order to reach the whole respiratory tract or intranasally (IN), administered to the URT only. AE delivery by vibrating mesh nebulizer generated droplets of $\sim 4.5 \mu \mathrm{m}$ diameter capable of reaching the entire LRT as well as the URT ${ }^{32}$. IN delivery was performed with a mucosal atomization device (MAD) generating droplets of 80 to $100 \mu \mathrm{M}$ diameter delivered in $300 \mu \mathrm{l}$ volume in order to restrict the vaccine's deposition to the URT. pH1N1 infected, and unimmunized pigs were used as controls. The pigs were culled 4 weeks after the immunization and tissues collected for evaluation of immune responses in the respiratory tract, draining lymph nodes, spleen and blood.

The antibody response after $\mathrm{pH} 1 \mathrm{~N} 1$ infection and ChAdOx2-NPM1-NA vaccination was evaluated in serum. Virus specific IgG was measured by end point titer ELISA against $\mathrm{H} 1 \mathrm{~N} 1 \mathrm{pdm} 09$ (pH1N1), which is an H1N1 Influenza A virus strain from the 2009 pandemic, and 
H3N2 (Fig. 1b). Serum pH1N1 specific IgG was detectable from day 7, reaching a plateau at $21-28$ DPI (1:12,800 and 1:13,056 respectively) and was similar in all animals until 28 DPI. Cross reacting antibodies specific for H3N2 were also detectable and reached a peak of 1:3,600 at $21 \mathrm{DPI}$. After immunization, Ab titers were highest to both $\mathrm{pH} 1 \mathrm{~N} 1$ and $\mathrm{H} 3 \mathrm{~N} 2$ in the IM group, reaching a peak of 1:58,000 and 1:38,000 respectively at 35 DPI (7 days after immunization, $p<0.0001$ ) (Fig. 1b, Table 1). The titers declined over time but remained significantly higher compared to the control and IN groups until the end of the study. The AE immunization induced the second highest response to $\mathrm{pH} 1 \mathrm{~N} 1$ and $\mathrm{H} 3 \mathrm{~N} 2$ which peaked at 42 DPI $(1: 25,000)$ and $49 \mathrm{DPI}(1: 25,000)$, respectively and was significantly higher compared to both the IN and control groups $(\mathrm{p}=0.0057$ and 0.0103 respectively for $\mathrm{pH} 1 \mathrm{~N} 1$ and $\mathrm{p}<0.0001$ for both groups for H3N2). Significant differences between groups are shown in Table 1. Intranasal immunization did not boost pH1N1 or H3N2 specific serum response (Fig. 1b).

We also measured the ELISA serum response to recombinant NA from H3N2 (N2), which peaked in the IM group at $49 \mathrm{DPI}$ (Fig. 1b. A lower N2 response but with a similar kinetic was detected in the $A E$ group, while the response after IN immunization was minimal, with only a small increase at $56 \mathrm{DPI}$. The functional activity of the serum antibodies was evaluated by microneutralization (MN). MN serum titers peaked at $14 \mathrm{DPI}$ for both $\mathrm{pH} 1 \mathrm{~N} 1$ and H3N2 and were maintained until the end of the study 56 DPI (Fig. 1c). No increase in pH1N1 MN titer was observed after immunization by any route. Although H3N2 MN titers were lower compared to $\mathrm{pH} 1 \mathrm{~N} 1$, the IM immunization significantly boosted the response at $49 \mathrm{DPI}$ (21 days post immunization, mean of $50 \%$ inhibition $1: 35)$.

In contrast, in the bronchoalveolar lavage (BAL) fluid, $A E$ immunization induced significantly higher $\lg \mathrm{G}$ and $\lg \mathrm{A}$ to both $\mathrm{pH} 1 \mathrm{~N} 1$ and $\mathrm{H} 3 \mathrm{~N} 2$ compared to the other groups (Fig. 2a). Similarly, $\mathrm{AE}$ immunization induced a significantly greater $\lg \mathrm{A} \mathrm{pH} 1 \mathrm{~N} 1$-specific response in nasal swabs on $56 \mathrm{DPI}$. The neutralizing titer in BAL was low for both pH1N1 and H3N2 with no difference between groups (Fig. 2b).

In summary, after pH1N1 pre-exposure IM immunization with ChAdOx2-NPM1-NA induced high serum IgG titers against both $\mathrm{pH} 1 \mathrm{~N} 1$ and $\mathrm{H} 3 \mathrm{~N} 2$, while $\mathrm{AE}$ delivery induced high 
$\lg G$ and $\lg A$ titers in BAL and nasal swabs. A significant increase in the serum neutralizing H3N2 Ab titer was detected only in the IM group.

\section{Cytokine responses in PBMC and tissues}

IFNy ELISpot was performed to assess the cytokine producing cells in PBMC, spleen, BAL and tracheobronchial, prescapular and retropharyngeal lymph nodes, draining the sites of immunization. Responses were evaluated following stimulation with $\mathrm{pH} 1 \mathrm{~N} 1$ and H3N2 live viruses or peptides covering the NP, M1 and NA proteins present in the vaccine. After pH1N1 challenge the first IFNy responses to $\mathrm{pH} 1 \mathrm{~N} 1, \mathrm{H} 3 \mathrm{~N} 2, \mathrm{M} 1$ and $\mathrm{NP}$ in PBMC were detected at 7 DPI as previously reported ${ }^{35,36}$.

IM immunization significantly increased the response in PBMC to NP (mean 653 SFC/ $10^{6}$ cells at $\left.35 \mathrm{DPI}\right), \mathrm{M} 1$ (477 SFC/ $10^{6}$ cells at $\left.35 \mathrm{DPI}\right), \mathrm{pH} 1 \mathrm{~N} 1$ (460 SFC/ $10^{6}$ cells at 49 DPI) and $\mathrm{H} 3 \mathrm{~N} 2$ (321 SFC/106 cells at $49 \mathrm{DPI}$ ) (Fig. 3). IM immunization also induced the greatest response to NA 7 days post immunization (mean 222 SFC/ $10^{6}$ cells at $35 \mathrm{DPI}$ ), although this rapidly declined, in contrast to the NP, M1, pH1N1 and H3N2 responses which were maintained until $56 \mathrm{DPI}$. Significant responses were reached at different time points after immunization and indicated in Table 1 and Table 2.

AE immunization induced significantly greater responses to NP, M1, $\mathrm{pH} 1 \mathrm{~N} 1$ and $\mathrm{H} 3 \mathrm{~N} 2$ in BAL compared to the other groups (Fig. 4). The response to NA was highest in the AE group in tracheobronchial lymph nodes. IM immunization induced a higher response in the spleen, but the increase was not significant. IN immunization did not induce a significant immune response compared to the other groups.

We also analyzed IFNy, TNF and IL-2 production of CD8 $\beta$ and CD4 T cells by intracellular cytokine staining (ICS) following in vitro stimulation with $\mathrm{pH} 1 \mathrm{~N} 1, \mathrm{H} 3 \mathrm{~N} 2$, NP and M1 (gating strategy Suppl. Fig. 2). AE immunization induced the largest numbers of pH1N1 and H3N2 specific IFNY and TNF secreting CD4 and CD8 cells in BAL (Fig. 5). BAL was the only tissue where IFNy/TNF co-producing cells were detected, with the AE group exhibiting the highest frequencies of $\mathrm{pH} 1 \mathrm{~N} 1$ specific $(0.37 \%)$ and $\mathrm{M} 1$ specific $(1.89 \%)$ double producing 
CD4 and CD8 T cells respectively, compared to the other groups (Fig. 5). The frequencies of pH1N1 specific CD4 IFNy and H3N2 specific CD4 TNF producing cells were significantly higher in tracheobronchial lymph nodes in AE immunized pigs (Fig. 5b). In nasal turbinates both $\mathrm{AE}$ and IN immunizations induced strong IFNY production in pH1N1-stimulated CD4 (1.67\% and $2.1 \%$, respectively) and CD8 $(2.31 \%$ and $1.19 \%$, respectively) cells. IN induced high IL-2 frequencies in pH1N1-stimulated CD4 (0.24\%) and CD8 (1.04\%) cells as well (Fig. 6B). IFNy was the dominant cytokine produced in the spleen with all immunization routes inducing stronger CD4 and CD8 IFNy responses to pH1N1 than the control, even though statistical significance was not reached (Fig. 6).

These data indicate that IM immunization induced a strong IFNY response in PBMC, while AE induced the highest IFNY response and IFNY/TNF co-producing cells in the BAL. The greatest response was to NP, followed by $M 1$ with the lowest response to NA. IN and $A E$ delivery induced comparable IFNy response in nasal turbinates.

\section{Discussion}

To mimic the effect of pre-existing immunity on vaccine induced immune responses we exposed pigs to $\mathrm{pH} 1 \mathrm{~N} 1$, which maintains antigenic similarity to human seasonal strains and provides a unique opportunity to use a virus affecting both humans and swine. We showed that ChAdOx2-NPM1-NA induced T cell and Ab responses after $\mathrm{pH} 1 \mathrm{~N} 1$ pre-exposure. We evaluated the importance of the route of immunization and targeting different regions of the respiratory tract on the magnitude and nature of immune responses. We used IN delivery with a mucosal atomisation device to restrict the antigen to the URT, and AE delivery by vibrating mesh nebuliser to distribute the vaccine throughout the LRT and URT ${ }^{32}$. Respiratory tract was compared to IM administration, the most widely used route of vaccine delivery. We showed that IM immunization after $\mathrm{pH} 1 \mathrm{~N} 1$ pre-exposure boosted blood $\mathrm{T}$ cell and $\mathrm{Ab}$ responses but had a weak effect on the BAL response. In contrast, AE immunization boosted local BAL T cell and Ab responses, but had no effect on the blood response, as we have previously observed with a different vaccine candidate ${ }^{34}$. It should be noted that $A E$ immunization 
delivers only a third of the dose so that this route appears to be extremely efficient in inducing immune responses ${ }^{32}$. IN immunization increased the $\mathrm{pH} 1 \mathrm{~N} 1$ specific $\mathrm{T}$ cell response in the nasal turbinates and spleen only marginally.

It was important to determine whether pre-exposure to conserved proteins such as NP and $\mathrm{M} 1$ (95\% conserved between strains) interfered with the immune response to an antigen, NA, to which the animals had not been previously exposed. This did not seem to be the case as the animals generated an anti-N2 antibody response, which could have contributed to the neutralization of H3N2. IFNY and TNF T cell responses against NP and M1 were significantly boosted in blood and BAL, while there was an anti-NA response in TBLN four weeks post $A E$ immunization and transient response in PBMC one week after IM immunization, although this was weaker than the NP and M1 response. Therefore, $\mathrm{pH} 1 \mathrm{~N} 1$ pre-exposure did not appear to hinder responses induced by ChAdOx2- NPM1-NA.

Few studies have evaluated the immunological impact of prior influenza exposure on vaccine efficacy in large animal models. Chepkwony et al demonstrated that prior H3N2 exposure followed by intramuscular immunization with whole inactivated heterologous H3N2 vaccine induced stronger and broader antibody responses ${ }^{37}$. Ferrets with pre-existing immune responses influenced recombinant $\mathrm{H} 2$ antibodies following vaccination ${ }^{38}$. In humans the first exposure to influenza virus biases the subsequent responses to heterologous strain and the breadth of cross reactivity ${ }^{1,2,3,4}$. This may partly explain the variable efficacy of traditional, intra-muscular inactivated seasonal human influenza vaccine which provide between $10-60 \%$ protective efficacy. Furthermore, prior vaccinations can have a significant negative impact on antibody binding, antibody affinity maturation and hemagglutinin inhibition responses to $\mathrm{H} 1 \mathrm{~N} 1, \mathrm{H} 3 \mathrm{~N} 2$ and $\mathrm{B}$ strains by inactivated vaccine platforms ${ }^{39,40}$. The response to $\mathrm{N} 2$ reported here may suggest that using a viral vector (ChAdOx2) may circumvent the poor response to heterologous antigen.

In humans an alternative immunization strategy is the use of LAIV administered intranasally with an efficacy of $75-80 \%$ in children, which induces a wider range of cellular, 
humoral, and mucosal immune responses than the inactivated vaccine ${ }^{41}$. Pre-existing immunity, due to natural exposure or prior vaccination, may significantly impact the ability of the LAIV vaccine strain to replicate and therefore impair vaccine efficacy ${ }^{42}$. This is supported by the observations that LAIV is less effective in young adults than children and ineffective in adults $>50$ years ${ }^{41}$. A clinical trial in Bangladesh correlated higher pre-existing baseline antibodies derived from natural influenza $\mathrm{A} / \mathrm{H} 3 \mathrm{~N} 2$ and $\mathrm{B}$ infections with low viral shedding/replication of LAIV ${ }^{43}$. The strong responses we detect in IM and AE animals suggest that ChAdOx2-NPM1-NA is not easily inhibited by prior responses to the influenza.

It is not known whether it is important to target different regions of the respiratory tract to induce optimal protection against different respiratory infections. Restricting the response to the URT, by administering a smaller volume intranasally, as in the case of LAIV, may not be optimal for lung protection, as studies in mice and ferrets suggest that induction of cross protective immunity against different types of influenza viruses is achieved most efficiently following vaccine delivery to the LRT ${ }^{24,44}$. However, a barrier to delivering existing LAIV to the LRT is that LAIV retains some potential to replicate, raising safety concerns for lung delivery ${ }^{20}$. However, this is not a problem for replication deficient viral vectored vaccines such as ChAdOx2-NPM1-NA. Therefore, it remains to be formally tested in challenge studies whether lung or URT targeting would be most effective for a vaccine directed against a respiratory pathogen. Additionally, combining systemic and respiratory immunization maybe a promising strategy requiring further investigation ${ }^{34}$.

Respiratory viruses are amongst the greatest threat to global health. Therefore, there is an urgent need to better understand the mechanism of protective immunity to respiratory infections and to develop better animal models to test efficacy of novel vaccines and therapies. Mice, guinea pigs, and ferrets are widely used for influenza virus research, but none of these small animal models accurately reflect the immune response in humans, particularly humans with pre-existing immunity. Pigs are an important natural host since they are susceptible to infection with many human seasonal strains and are a source of new human pandemic viruses. In this study we demonstrated distinct immune responses to our candidate vaccine 
as a result of immunization route. We chose a pig model with pre-exposure to a heterologous influenza strain, to best mimic adult human influenza A virus exposure. Whilst we showed the route of immunization had a significant impact on the type of immune response generated it remains to be seen which may correlate best with protective efficacy. We demonstrate that ChAdOx2-NPM1-NA was immunogenic after pre-exposure, resulting in both $\mathrm{T}$ cell immunogenicity and anti-NA antibody generation. We propose that the pig is a powerful model to dissect systemic and respiratory tract immune responses after influenza pre-exposure and immunization. Our data suggests that the immune responses arising from multiple routes of administration of ChAdOx2 NPM1-NA warrant further study to determine protective efficacy. These studies will provide valuable insight into the development of universal influenza, and other respiratory viruses vaccines and inform future vaccine and clinical trial design. 


\section{Materials and Methods}

\section{ChAdOx2 viral vectored vaccines}

ChAdOx2 is a replication-deficient (E1 and E3 deleted) simian adenovirus ${ }^{45}$, which we engineered to express swine Influenza A virus nucleoprotein (NP) and matrix 1 (M1) as a fusion protein (NPM1) and/or NA. The NP and M1 protein ORFs from A/swine/England/1353/2009 (GenBank accession number KR701098 and KR701100) fused together by a glycine linker was synthesized by GeneArt Gene Synthesis (Thermo Fisher Scientific). The neuraminidse (N2) from H3N2 strain A/sw/Ohio/A01354299/2017 (GenBank accession number MF801571) was codon optimised for expression in domestic pigs and synthesized by GeneArt Gene Synthesis. The Influenza virus genes were inserted into a Gateway ${ }^{\circledR}$ recombination shuttle plasmid (pENTR LPTOS), containing a human cytomegalovirus major immediate early promoter (IE CMV), which includes intron A and two tetracycline operator 2 sites, and the bovine growth hormone polyadenylation signal, either by homologous recombination using NEBuilder® HiFi DNA assembly kit (New England Biolabs) or classical restriction enzyme cloning. A shuttle plasmid containing N2 linked to NPM1 via the $2 \mathrm{~A}$ ribosome skipping sequence from foot and mouth disease virus (FMDV) was generated by a 3 fragment ligation using NEBuilder® HiFi DNA assembly kit. Briefly, pENTR LPTOS-NA was digested with Kpnl the recognition sequence of which is upstream of the NA ORF, this was joined to the HindIII-Notl fragment NPM1 from the shuttle plasmid pENTR LPTOS-NPM1 described above contains homology to the shuttle vector at the 5'end and $2 \mathrm{~A}$ sequence which was amplified from a previous construct using primers with 5' homology to 3' NPM1 excluding the stop codon and 3' homology to the 5' NA excluding the start codon.

BACs containing the ChAdOx2 NPM1, ChAdOx2 NA or ChAdOx2 NPM1-2A-N2 were prepared by Gateway® recombination between the ChAdOx2 destination DNA BAC vector as previously descried ${ }^{46}$ and the shuttle plasmids containing the influenza virus gene expression cassettes using standard protocols resulting in the insertion of the expression cassette at the E1 locus. The ChAdOx2 adenovirus genomes were excised from the BAC using unique Pacl sites flanking the adenovirus genome sequence. ChAdOx2 NPM1, ChAdOx2-N2 or ChAdOx2 
NPM1-2A-N2 viral vectors were rescued in T-REx ${ }^{\text {TM }}$ cells (Invitrogen, Cat. R71007), a derivative of HEK293 cells which constitutively express the Tet repressor protein and prevent antigen expression during virus production. The resultant viruses, ChAdOx2 NPM1, ChAdOx2-N2 or ChAdOx2 NPM1-2A-N2, were purified by $\mathrm{CsCl}$ gradient ultracentrifugation as described previously ${ }^{47}$. The titres were determined on T-REx ${ }^{\mathrm{TM}}$ cells using anti-hexon immunostaining assay based on the QuickTiter ${ }^{\mathrm{TM}}$ Adenovirus Titer Immunoassay kit (Cell Biolabs Inc).

\section{Vaccine and virus challenge}

Pigs were infected with the swine isolate H1N1 A/swine/England/1353/2009 (pH1N1), provided by the Animal and Plant Health Agency (APHA) (DEFRA swine influenza A virus surveillance programme SV3041).

\section{Animals, influenza challenge and immunization}

The animal experiment was approved by the ethical review process at APHA and followed the UK Government Animal (Scientific Procedures) Act 1986. Twenty, 7-week-old female Landrace $x$ Large White pigs, were pre-screened for the absence of influenza A virus antibody reactivity by $\mathrm{HAl}$ with four swine Influenza A virus antigens: H1N1pdm09, H1N2, H3N2 and avian-like H1N1. One week after acclimatization, all twenty pigs were inoculated intranasally with $7.76 \times 10^{6} \mathrm{TCID}_{50} \mathrm{pH} 1 \mathrm{~N} 1$ in a total of $4 \mathrm{ml}(2 \mathrm{ml}$ per nostril using a mucosal atomization device (MAD, Wolfe-Tory Medical). Following H1N1pdm09 (pH1N1) challenge, daily nasal swabs were collected for 7 days to assess the virus load by plaque assays as previously described ${ }^{33}$.

Four weeks post $\mathrm{pH} 1 \mathrm{~N} 1$ challenge, the animals were randomly assigned to four groups and immunized with the same dose of $5 \times 10^{8}$ infectious units (IU) ChAdOx2-NPM1-NA as follows: 1) intramuscularly (IM) with $1 \mathrm{ml}$ administered in each trapezius muscle behind the ear); 2) aerosol (AE) with $1 \mathrm{ml}$ administered over 2-5 minutes using an Aerogen Solo vibrating mesh nebulizer (Aerogen, Dangan, Galway, Ireland) ${ }^{32}$; 3) intranasally (IN) with $300 \mu$ per 
nostril administered with a MAD, with the aim of restricting the vaccine to the upper respiratory tract $^{32}$ and 4) unimmunized controls. The animals in the IN and AE groups were anaesthetized with a mixture of $5 \mathrm{mg} / \mathrm{kg}$ Zoletil $(2.5 \mathrm{mg} / \mathrm{kg}$ of Tiletamine $+2.5 \mathrm{mg} / \mathrm{kg}$ of Zolazepam) and 0.05 $\mathrm{mg} / \mathrm{kg}$ Domitor (medetomidine).

Blood was collected weekly to assess immune responses of peripheral blood mononuclear cells (PBMC) and antibodies serum. Four weeks post immunization all animals were humanely culled with an overdose of pentobarbital sodium anaesthetic. Blood, bronchoalveolar lavage (BAL), spleen, tracheobronchial lymph nodes (TBLN), prescapular LNs, retropharyngeal LNs and nasal turbinates (NT) were collected and processed as described before ${ }^{33,34}$.

\section{Serological assays}

Endpoint titer ELISAs and microneutralization (MN) assays for $\mathrm{pH} 1 \mathrm{~N} 1$ and $\mathrm{H} 3 \mathrm{~N} 2$ viruses were performed as described before ${ }^{48}$. In addition, Abs against recombinant N2 protein were measured in serum. Recombinant NA (N2) (sequence matched to the vaccine antigen, Genbank accession number: ATE49827) was produced by The Native Antigen company

\section{IFNy ELISpots}

Cryopreserved isolated from PBMC, BAL, TBLN, prescapular LN and spleen cells were used to assay the frequencies of IFNY secreting cells. MultiScreen-HA ELISPOT plates (Merck Millipore) were coated with $0.5 \mathrm{mg} / \mathrm{ml}$ anti-pig IFNy (clone P2G10; BD Pharmingen) diluted in carbonate buffer at $4^{\circ} \mathrm{C}$ overnight. The following day the plates were washed 4 times with PBS (no tween) and blocked for at least 1 hour at $37^{\circ} \mathrm{C}$ with culture medium (RPMI 1640 with stable glutamine supplemented with $10 \%$ fetal calf serum (FCS), $100 \mathrm{U} / \mathrm{ml}$ penicillin and 100 $\mathrm{mg} / \mathrm{ml}$ streptomycin). After 4 washes with PBS, cells resuspended in culture medium were seeded in triplicates at $3 \times 10^{5}$ cells per well. The cells were simulated either with $\mathrm{pH} 1 \mathrm{~N} 1$ or H3N2 (multiplicity of infection [MOI] of 1), $3 \mu \mathrm{g} / \mathrm{ml}$ ConA (positive control, Sigma-Aldrich), culture medium (negative control) or with one of the following pools of peptides at a 
concentration of $2 \mu \mathrm{g} / \mathrm{ml}$; NP1, NP2, M1, NA1 and NA2 (Supplementary Table 1). The plates were incubated for $40 \mathrm{~h}$ in a $37^{\circ} \mathrm{C}, 5 \% \mathrm{CO}_{2}$ incubator. The plates were washed with PBS, $0.05 \%$ Tween 20 and incubated for 1.5 hours at room temperature with $0.25 \mathrm{mg} / \mathrm{ml}$ biotinylated anti-pig IFNy detection Ab (clone P2C11, BD Pharmingen) diluted in PBS supplemented with $0.01 \%$ Tween 20 and $0.1 \%$ BSA, followed by a 1 -hour incubation at room temperature with streptavidin-alkaline phosphatase (1:2000 in PBS, 0.01\% Tween20, 0.1\% BSA, Roche, Mannheim, Germany). Spots were visualized after addition of 5-bromo-4-chloro-3-indolyl

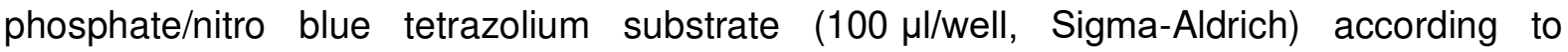
manufacturer's instructions. The reaction was stopped using tap water and the spots were counted using the AID ELISPOT reader (AID Autoimmun Diagnostika). Results were expressed as number of IFNy producing cells per $10^{6}$ cells after subtraction of the number of IFNY-producing cells in medium control wells. Results from NP1 and NP2 or NA1 and NA2 were pooled and shown as NP and NA, respectively.

\section{Intracellular cytokine staining (ICS)}

Cryopreserved cells from BAL, spleen, nasal turbinates, TBLN and prescapular LN were thawed and seeded $1 \times 10^{6}$ cells per well. The cells were stimulated overnight with $\mathrm{pH} 1 \mathrm{~N} 1$ or $\mathrm{H} 3 \mathrm{~N} 2(\mathrm{MOI}=1)$ or medium as a control at $37^{\circ} \mathrm{C}$ and $5 \% \mathrm{CO}_{2}$. Those stimulated with the NP2 or M1 peptide pools $(2 \mu \mathrm{g} / \mathrm{ml})$ were only incubated

for one hour before the addition of Brefeldin A (GolgiPlug ${ }^{\mathrm{TM}}$, BD Biosciences) as per manufacturer instructions. In some wells, a cocktail of phorbol 12-myristate 13-acetate (PMA)/lonomycin (Biolegend) was added as a positive control at the same time as the GolgiPlug. Duplicate wells, each containing $1 \times 10^{6}$ cells, were seeded for each stimulation condition. After four hours incubation at $37^{\circ} \mathrm{C}$, the cells were centrifuged for $4 \mathrm{~min}, 1500 \mathrm{rpm}$, washed twice with PBS and analysed for cytokine production using the antibodies listed in Table 3. Briefly, cells were stained with the primary Abs for surface staining and with NearInfrared Fixable LIVE/DEAD stain (Invitrogen), for identification of live cells. Following a 20 min incubation at $4^{\circ} \mathrm{C}$ cells were washed twice, fixed and permeabilised with $\mathrm{BD}$ 
Cytofix/Cytoperm (BD Biosciences) as per the manufacturer's instructions. Cells were incubated for 30 min at $4{ }^{\circ} \mathrm{C}$ with the directly conjugated cytokine antibodies, washed, resuspended in PBS, and analysed using a MACSquant analyser10 (Miltenyi).

\section{Statistical analysis}

Statistical analyses were performed using GraphPad Prism 8.1.2 (GraphPad Software, San Diego, CA, United States). The data sets were first analyzed for normality and then subjected to a two-way ANOVA and Bonferroni's multiple comparisons test. Significant differences were either depicted on the graph or listed in Table 1 and Table $2\left({ }^{*} p<0.05,{ }^{* *} p<0.01,{ }^{* * *} p<0.001\right.$, $\left.{ }^{* * * *} \mathrm{p}<0.0001\right)$. Until $28 \mathrm{DPI}$, all animals were treated identically and significant differences between the groups were not identified.

\section{Data Availability}

Data generated or analyzed during this study that are critical to the reported findings are available within the article and its Supplementary Information files. Additional supporting data are available from the corresponding authors without undue reservation. 
Table 1. Significant differences between the four groups at the same time-point after immunization.

\begin{tabular}{|c|c|c|c|c|c|}
\hline \multirow{2}{*}{\multicolumn{2}{|c|}{ Assays }} & \multicolumn{4}{|c|}{ Significances identified between groups post immunization } \\
\hline & & \multirow[b]{2}{*}{$\begin{array}{c}\text { Day 35 } \\
I \mathrm{IM}>\mathrm{AE} \\
(\mathrm{P}=0.001) \\
\mathrm{IM}>\mathrm{IN} \\
(\mathrm{P}=0.001) \\
\mathrm{IM}>\mathrm{C} \\
(\mathrm{P}=0.001)\end{array}$} & \multirow[b]{2}{*}{$\begin{array}{c}\text { Day 42 } \\
I \mathrm{I}>\mathrm{AE} \\
(\mathrm{P}=0.0002) \\
\mathrm{IM}>\mathrm{IN} \\
(\mathrm{P}=0.0001) \\
\mathrm{IM}>\mathrm{C} \\
(\mathrm{P}=0.0001) \\
\mathrm{AE}>\mathrm{IN} \\
(\mathrm{P}=0.006) \\
\mathrm{AE}>\mathrm{C}(\mathrm{P}=0.01)\end{array}$} & \multirow[b]{2}{*}{$\begin{array}{c}\text { Day 49 } \\
\text { IM>IN } \\
(P=0.0003) \\
I M>C \\
(P=0.0002) \\
B A L>T B L N \\
(P=0.01)\end{array}$} & \multirow{2}{*}{$\begin{array}{c}\text { Day 56 } \\
I M>I N(P=0.02) \\
I M>C(P=0.02)\end{array}$} \\
\hline $\begin{array}{l}\text { ELISA } \\
\text { IgG } \\
\text { (Figure } \\
\text { 1B) }\end{array}$ & H1N1 & & & & \\
\hline & H3N2 & $\begin{array}{c}I \mathrm{IM}>\mathrm{AE} \\
(\mathrm{P}=0.0001) \\
\mathrm{IM}>\mathrm{IN} \\
(\mathrm{P}=0.0001) \\
\mathrm{IM}>\mathrm{C} \\
(\mathrm{P}=0.0001) \\
\mathrm{AE}>\mathrm{C}(\mathrm{P}=0.03)\end{array}$ & $\begin{array}{c}I \mathrm{IM}>\mathrm{AE} \\
(\mathrm{P}=0.0001) \\
\mathrm{IM}>\mathrm{C} \\
(\mathrm{P}=0.0001) \\
\mathrm{AE}>\mathrm{IN} \\
(\mathrm{P}=0.0033) \\
\mathrm{AE}>\mathrm{C} \\
(\mathrm{P}=0.0014)\end{array}$ & $\begin{array}{c}I M>I N \\
(P=0.0002) \\
I M>C \\
(P=0.0001) \\
A E>I N \\
(P=0.0001) \\
A E>C \\
(P=0.0001)\end{array}$ & $\begin{array}{l}A E>I N(P=0.05) \\
A E>C \quad(P=0.05)\end{array}$ \\
\hline & N2 & $\begin{array}{c}\text { no significance } \\
(P>0.05)\end{array}$ & $\begin{array}{l}\text { no significance } \\
\quad(P>0.05)\end{array}$ & $\begin{array}{c}\mathrm{IM}>\mathrm{AE} \\
(\mathrm{P}=0.0001) \\
\mathrm{IM}>\mathrm{IN} \\
(\mathrm{P}=0.0001) \\
\mathrm{IM}>\mathrm{C} \\
(\mathrm{P}=0.0001)\end{array}$ & $\begin{array}{c}I M>A E(P=0.0001) \\
I M>I N(P=0.0001) \\
I M>C \quad(P=0.0001)\end{array}$ \\
\hline $\begin{array}{l}\text { MN } \\
\text { H3N2 } \\
\text { (Figure } \\
\text { 1C) }\end{array}$ & & $\begin{array}{c}\text { no significance } \\
(P>0.05)\end{array}$ & $\begin{array}{c}I \mathrm{IM}>\mathrm{AE} \\
(\mathrm{P}=0.0001) \\
\mathrm{IM}>\mathrm{IN} \\
(\mathrm{P}=0.0001) \\
\mathrm{IM}>\mathrm{C} \\
(\mathrm{P}=0.0001)\end{array}$ & $\begin{array}{c}I \mathrm{IM}>\mathrm{AE} \\
(\mathrm{P}=0.001) \\
\mathrm{IM}>\mathrm{IN} \\
(\mathrm{P}=0.001) \\
\mathrm{IM}>\mathrm{C} \\
(\mathrm{P}=0.001)\end{array}$ & $\begin{array}{c}\text { no significance } \\
\quad(P>0.05)\end{array}$ \\
\hline \multirow[t]{3}{*}{$\begin{array}{l}\text { ELISpots } \\
\text { (Figure 3) }\end{array}$} & NP & $\begin{array}{c}\mathrm{IM}>\mathrm{AE} \\
(\mathrm{P}=0.04) \\
\mathrm{IM}>\mathrm{C} \\
(\mathrm{P}=0.02)\end{array}$ & $\begin{array}{c}\text { no significance } \\
(P>0.05)\end{array}$ & $\begin{array}{c}\mathrm{IM}>\mathrm{AE} \\
(\mathrm{P}=0.003) \\
\mathrm{IM}>\mathrm{C} \\
(\mathrm{P}=0.002)\end{array}$ & $\begin{array}{c}\mathrm{IM}>\mathrm{AE}(\mathrm{P}=0.03) \\
I \mathrm{IM}>\mathrm{C} \\
(\mathrm{P}=0.009)\end{array}$ \\
\hline & NA & $\begin{array}{c}\text { no significance } \\
(P>0.05)\end{array}$ & $\begin{array}{c}\text { no significance } \\
(P>0.05)\end{array}$ & $\begin{array}{c}\text { no significance } \\
(P>0.05)\end{array}$ & $\begin{array}{c}\mathrm{IM}>\mathrm{C} \\
(\mathrm{P}=0.006)\end{array}$ \\
\hline & pH1N1 & $\begin{array}{c}\text { no significance } \\
(P>0.05)\end{array}$ & $\begin{array}{l}\text { no significance } \\
\quad(P>0.05)\end{array}$ & $\begin{array}{c}\mathrm{IM}>\mathrm{C} \\
(\mathrm{P}=0.01)\end{array}$ & $\begin{array}{c}\mathrm{IM}>\mathrm{C} \\
(\mathrm{P}=0.07)\end{array}$ \\
\hline
\end{tabular}


Table 2. Significant differences in the same group between different timepoints after immunization for Figure 3.

\begin{tabular}{|c|c|c|c|}
\hline Peptides / Groups & IM & AE & C \\
\hline NP & $\begin{array}{c}35 \mathrm{DPl}>28 \mathrm{DPI} \\
(\mathrm{p}<0.01) \\
49 \mathrm{DPl}>28 \mathrm{DPI} \\
(p<0.01)\end{array}$ & & \\
\hline M1 & $\begin{array}{c}35 \mathrm{DPl}>28 \mathrm{DPI} \\
(p<0.0001) \\
49 \mathrm{DPl}>28 \mathrm{DPI} \\
(p<0.0001) \\
56 \mathrm{DPl}>28 \mathrm{DPI} \\
(p<0.0001) \\
35 \mathrm{DPl}>42 \mathrm{DPI} \\
(p<0.05)\end{array}$ & & \\
\hline NA & $\begin{array}{c}35 \mathrm{DP} \mathrm{l}>28 \mathrm{DPI} \\
(\mathrm{p}<0.05) \\
35 \mathrm{DPl}>42 \mathrm{DPI} \\
(\mathrm{p}<0.01)\end{array}$ & $\begin{array}{c}35 \mathrm{DPI}>42 \mathrm{DPI} \\
(\mathrm{p}<0.05)\end{array}$ & $\begin{array}{c}35 \mathrm{DPI}>49 \mathrm{DPI} \\
(p<0.05) \\
35 \mathrm{DPI}>56 \mathrm{DPI} \\
(p<0.001)\end{array}$ \\
\hline
\end{tabular}


Table 3. Antibodies used for the intracellular cytokine staining

\begin{tabular}{|c|c|c|c|c|c|}
\hline Antigen & Clone & Isotype & Fluorochrome & $\begin{array}{c}\text { Source of } \\
\text { primary } A b\end{array}$ & $\begin{array}{c}\text { Details of } \\
\text { secondary } A b\end{array}$ \\
\hline CD4 & $74-12-4$ & $\lg G 2 b$ & PerCP-Cy5.5 & BD Biosciences & \\
\hline $\mathrm{CD} 8 \mathrm{~b}$ & РPT23 & $\operatorname{lgG1}$ & FITC & $\begin{array}{c}\text { Bio-Rad } \\
\text { Laboratories }\end{array}$ & \\
\hline TNF & MAb11 & $\operatorname{lgG1}$ & BV421 & BioLegend & \\
\hline $\mathrm{IFN} \gamma$ & P2G10 & $\operatorname{lgG1}$ & $A P C$ & BD Biosciences & \\
\hline IL-2 & $\begin{array}{c}\text { A150D } 3 F 1 \\
2 \mathrm{H} 2\end{array}$ & $\lg G 2 a$ & PE-Cy7 & ThermoFisher & $\begin{array}{c}\text { rat-anti-mouse, } \\
\text { IgG2a, } \\
\text { BioLegend }\end{array}$ \\
\hline
\end{tabular}




\section{References:}

1. Fazekas de St, G. \& Webster, R.G. Disquisitions of Original Antigenic Sin. I. Evidence in man. J Exp Med 124, 331-345 (1966).

2. Gostic, K.M. et al. Childhood immune imprinting to influenza A shapes birth year-specific risk during seasonal H1N1 and H3N2 epidemics. PLoS Pathog 15, e1008109 (2019).

3. Dugan, H.L. et al. Preexisting immunity shapes distinct antibody landscapes after influenza virus infection and vaccination in humans. Sci Trans/ Med 12 (2020).

4. Knight, M., Changrob, S., Li, L. \& Wilson, P.C. Imprinting, immunodominance, and other impediments to generating broad influenza immunity. Immunol Rev 296, 191-204 (2020).

5. Sridhar, S. et al. Cellular immune correlates of protection against symptomatic pandemic influenza. Nat Med 19, 1305-1312 (2013).

6. Wilkinson, T.M. et al. Preexisting influenza-specific CD4+ T cells correlate with disease protection against influenza challenge in humans. Nat Med 18, 274-280 (2012).

7. Hayward, A.C. et al. Natural T Cell-mediated Protection against Seasonal and Pandemic Influenza. Results of the Flu Watch Cohort Study. Am J Respir Crit Care Med 191, 1422-1431 (2015).

8. McMichael, A.J., Gotch, F.M., Noble, G.R. \& Beare, P.A. Cytotoxic T-cell immunity to influenza. N Engl J Med 309, 13-17 (1983).

9. Coughlan, L. et al. Heterologous Two-Dose Vaccination with Simian Adenovirus and Poxvirus Vectors Elicits Long-Lasting Cellular Immunity to Influenza Virus A in Healthy Adults. EBioMedicine 29, 146-154 (2018).

10. Everett, H.E. et al. Vaccines That Reduce Viral Shedding Do Not Prevent Transmission of H1N1 Pandemic 2009 Swine Influenza a Virus Infection to Unvaccinated Pigs. J Virol (2020).

11. Chen, Y.Q. et al. Influenza Infection in Humans Induces Broadly Cross-Reactive and Protective Neuraminidase-Reactive Antibodies. Cell 173, 417-429 e410 (2018).

12. Krammer, F., Li, L. \& Wilson, P.C. Emerging from the Shadow of Hemagglutinin: Neuraminidase Is an Important Target for Influenza Vaccination. Cell Host Microbe 26, 712-713 (2019).

13. Jarjour, N.N., Masopust, D. \& Jameson, S.C. T Cell Memory: Understanding COVID-19. Immunity 54, 14-18 (2021). 
14. Snyder, M.E. \& Farber, D.L. Human lung tissue resident memory T cells in health and disease. Curr Opin Immunol 59, 101-108 (2019).

15. Mueller, S.N., Gebhardt, T., Carbone, F.R. \& Heath, W.R. Memory T cell subsets, migration patterns, and tissue residence. Annu Rev Immunol 31, 137-161 (2013).

16. Jin, H. \& Subbarao, K. Live attenuated influenza vaccine. Curr Top Microbiol Immunol 386, 181204 (2015).

17. Low, N. et al. A randomized, controlled trial of an aerosolized vaccine against measles. $N$ Engl J Med 372, 1519-1529 (2015).

18. Wu, S. et al. Safety, tolerability, and immunogenicity of an aerosolised adenovirus type-5 vector-based COVID-19 vaccine (Ad5-nCoV) in adults: preliminary report of an open-label and randomised phase 1 clinical trial. The Lancet Infectious Diseases.

19. Bolton, D.L., Song, K., Tomaras, G.D., Rao, S. \& Roederer, M. Unique cellular and humoral immunogenicity profiles generated by aerosol, intranasal, or parenteral vaccination in rhesus macaques. Vaccine 35, 639-646 (2017).

20. Ambrose, C.S. \& Coelingh, K.L. Small-particle aerosolization of live attenuated influenza vaccine virus. J Infect Dis 205, 348; author reply 348-349 (2012).

21. de Swart, R.L. et al. Needle-free delivery of measles virus vaccine to the lower respiratory tract of non-human primates elicits optimal immunity and protection. NPJ Vaccines 2, 22 (2017).

22. Hodge, L.M. \& Simecka, J.W. Role of upper and lower respiratory tract immunity in resistance to Mycoplasma respiratory disease. J Infect Dis 186, 290-294 (2002).

23. Ronan, E.O., Lee, L.N., Tchilian, E.Z. \& Beverley, P.C. Nasal associated lymphoid tissue (NALT) contributes little to protection against aerosol challenge with Mycobacterium tuberculosis after immunisation with a recombinant adenoviral vaccine. Vaccine 28, 5179-5184 (2010).

24. Lau, Y.F., Santos, C., Torres-Vélez, F.J. \& Subbarao, K. The magnitude of local immunity in the lungs of mice induced by live attenuated influenza vaccines is determined by local viral replication and induction of cytokines. J Virol 85, 76-85 (2011).

25. Smith, J.H. et al. Nebulized live-attenuated influenza vaccine provides protection in ferrets at a reduced dose. Vaccine 30, 3026-3033 (2012).

26. Hemmink, J.D. et al. Distinct immune responses and virus shedding in pigs following aerosol, intra-nasal and contact infection with pandemic swine influenza A virus, $A(H 1 N 1) 09$. Vet Res 47, 103 (2016). 
27. Minne, A. et al. The delivery site of a monovalent influenza vaccine within the respiratory tract impacts on the immune response. Immunology 122, 316-325 (2007).

28. Kaufman, D.R. et al. Trafficking of antigen-specific CD8+ T lymphocytes to mucosal surfaces following intramuscular vaccination. J Immunol 181, 4188-4198 (2008).

29. Kaufman, D.R., Bivas-Benita, M., Simmons, N.L., Miller, D. \& Barouch, D.H. Route of adenovirus-based HIV-1 vaccine delivery impacts the phenotype and trafficking of vaccineelicited CD8+ T lymphocytes. J Virol 84, 5986-5996 (2010).

30. Rajao, D.S. \& Vincent, A.L. Swine as a model for influenza A virus infection and immunity. ILAR J 56, 44-52 (2015).

31. Judge, E.P. et al. Anatomy and bronchoscopy of the porcine lung. A model for translational respiratory medicine. Am J Respir Cell Mol Biol 51, 334-343 (2014).

32. Martini, V. et al. Distribution of Droplets and Immune Responses After Aerosol and Intra-Nasal Delivery of Influenza Virus to the Respiratory Tract of Pigs. Front Immunol 11, 594470 (2020).

33. Holzer, B. et al. Comparison of Heterosubtypic Protection in Ferrets and Pigs Induced by a Single-Cycle Influenza Vaccine. J Immunol 200, 4068-4077 (2018).

34. Martini, V. et al. Simultaneous Aerosol and Intramuscular Immunization with Influenza Vaccine Induces Powerful Protective Local T Cell and Systemic Antibody Immune Responses in Pigs. J Immunol 206, 652-663 (2021).

35. Edmans, M. et al. Magnitude and Kinetics of $\mathrm{T}$ Cell and Antibody Responses During H1N1pdm09 Infection in Inbred Babraham Pigs and Outbred Pigs. Frontiers in Immunology 11 (2021).

36. Talker, S.C. et al. Influenza A Virus Infection in Pigs Attracts Multifunctional and Cross-Reactive T Cells to the Lung. J Virol 90, 9364-9382 (2016).

37. Chepkwony, S., Parys, A., Vandoorn, E., Chiers, K. \& Van Reeth, K. Efficacy of Heterologous Prime-Boost Vaccination with H3N2 Influenza Viruses in Pre-Immune Individuals: Studies in the Pig Model. Viruses 12 (2020).

38. Reneer, Z.B., Skarlupka, A.L., Jamieson, P.J. \& Ross, T.M. Broadly Reactive H2 Hemagglutinin Vaccines Elicit Cross-Reactive Antibodies in Ferrets Preimmune to Seasonal Influenza A Viruses. mSphere 6 (2021).

39. Khurana, S. et al. Repeat vaccination reduces antibody affinity maturation across different influenza vaccine platforms in humans. Nat Commun 10, 3338 (2019). 
40. Nachbagauer, R. et al. Defining the antibody cross-reactome directed against the influenza virus surface glycoproteins. Nat Immunol 18, 464-473 (2017).

41. Rhorer, J. et al. Efficacy of live attenuated influenza vaccine in children: A meta-analysis of nine randomized clinical trials. Vaccine 27, 1101-1110 (2009).

42. Roy, S., Williams, C.M., Wijesundara, D.K. \& Furuya, Y. Impact of Pre-Existing Immunity to Influenza on Live-Attenuated Influenza Vaccine (LAIV) Immunogenicity. Vaccines (Basel) 8 (2020).

43. Brickley, E.B. et al. The Effect of Preexisting Immunity on Virus Detection and Immune Responses in a Phase II, Randomized Trial of a Russian-Backbone, Live, Attenuated Influenza Vaccine in Bangladeshi Children. Clin Infect Dis 69, 786-794 (2019).

44. Baz, M. et al. Nonreplicating influenza A virus vaccines confer broad protection against lethal challenge. MBio 6, e01487-01415 (2015).

45. Folegatti, P.M. et al. Safety and Immunogenicity of a Novel Recombinant Simian Adenovirus ChAdOx2 as a Vectored Vaccine. Vaccines (Basel) 7 (2019).

46. Morris, S.J., Sebastian, S., Spencer, A.J. \& Gilbert, S.C. Simian adenoviruses as vaccine vectors. Future Virol 11, 649-659 (2016).

47. Cottingham, M.G. et al. Preventing spontaneous genetic rearrangements in the transgene cassettes of adenovirus vectors. Biotechnol Bioeng 109, 719-728 (2012).

48. McNee, A. et al. Establishment of a Pig Influenza Challenge Model for Evaluation of Monoclonal Antibody Delivery Platforms. J Immunol (2020).

\section{Acknowledgements}

We are grateful to the animal staff for providing excellent animal care. We also thank The Pirbright Institute Flow Cytometry Unit and Claire Powers and Louise Rose for producing the virus. We thank APHA for providing the swine A/swine/England/1353/2009 influenza virus 
strain (DEFRA surveillance programme SV3041). We wish to thank Dr Elsa Barrero at APHA for providing Veterinary expertise.

\section{Author contribution}

ET, SG and TL designed the study and obtained the funding; ERA, SM, RK, MU and AB generated the vaccine and carried out mouse experiments; EV, TM, AM, VC and RM designed and performed the pig experiments; EV, TM, ET, AM, VM, BP, VC, TC and EM processed samples; EV, TM and AM analysed the pig data; PD and HE oversaw the pig studies, infected and immunized the animals; ET, EV and ERA wrote the manuscript. All authors have read and approved the manuscript.

\section{Competing Interests}

The authors declare the following competing financial interests: SCG is co-founder of Vaccitech and named as an inventor on a patent covering use of ChAdOx2-vectored vaccines. TL is a consultant to Vaccitech. RM is an employee of Aerogen Limited.

\section{Funding}

This work was supported by the Medical Research Council (grant number MR/S037160/1) and UKRI Biotechnology and Biological Sciences Research Council (BBSRC) Institute Strategic Programme and Core Capability Grants to The Pirbright Institute (BBS/E///00007031 and BBS/E///00007037 and BBS/E/I/00007039). 
Figures

\section{Figure 1}

a

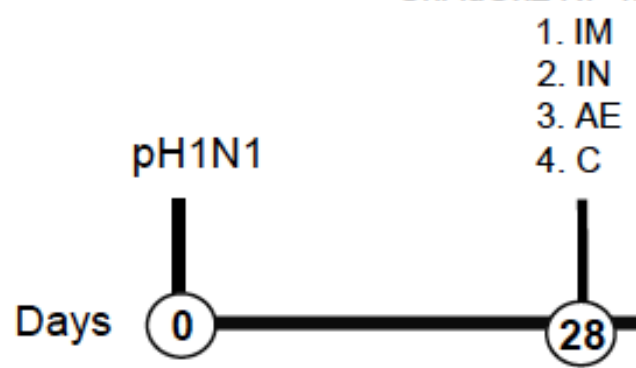

1. IM

2. IN

AE

4. C

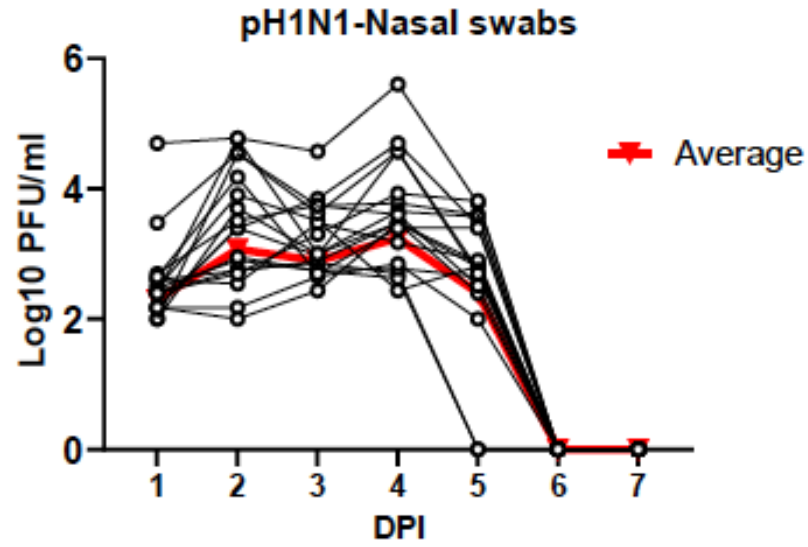

b

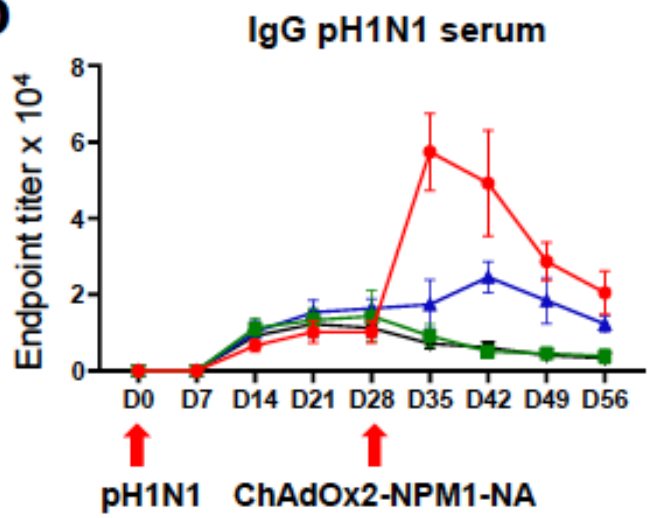

C

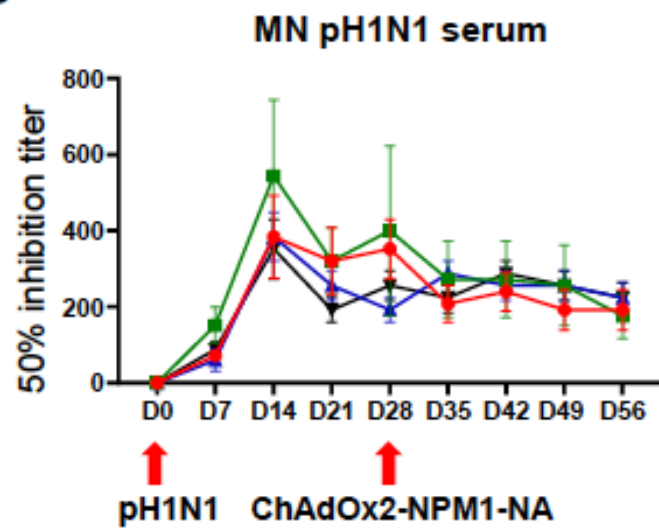

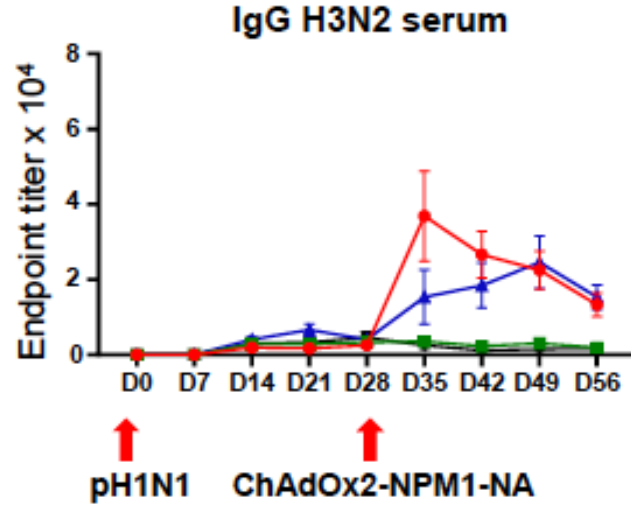

MN H3N2 serum

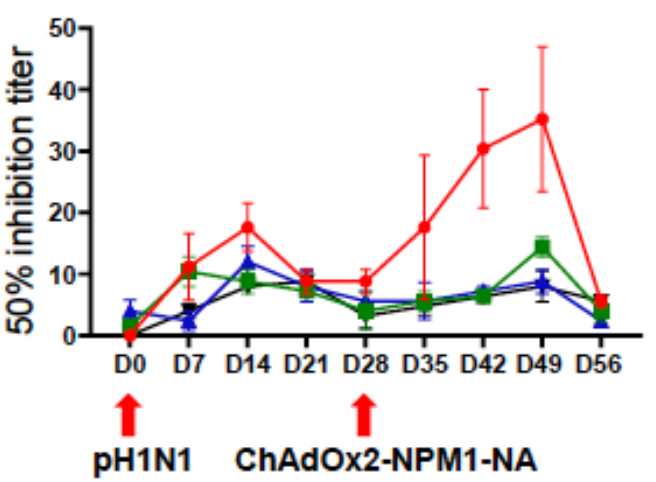

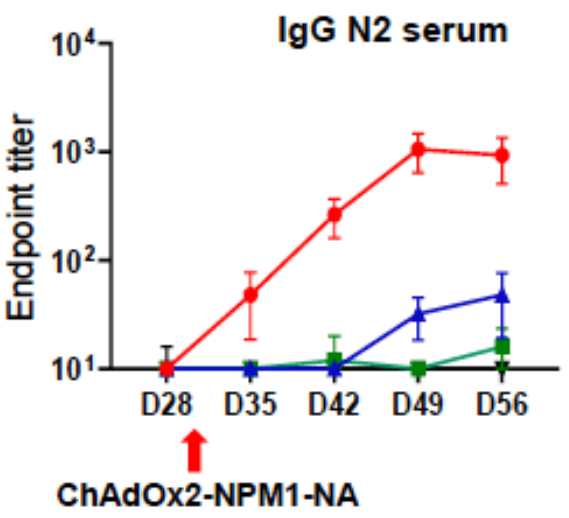

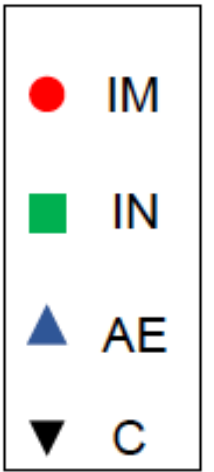

Figure 1

Experimental design, viral load and systemic antibody responses. a Twenty pigs were infected with pH1N1 Influenza A virus and four weeks later immunized with ChAdOx2 NPM1- NA intramuscularly (IM), intranasally (IN) or by aerosol (AE). Four weeks later they were culled. Weekly blood samples were 
collected during the time course. Control (C) animals were infected but not immunized. Virus load was determined by plaque assay of daily nasal swabs (NS) obtained at the indicated days post infection (DPI). Each black line represents one animal. The thick red line indicates the mean of 20 animals. $b$ pH1N1, H3N2 and N2 specific IgG responses in serum were determined by ELISA at the indicated time points. c Serum neutralizing titers over time were determined by microneutralization (MN) of pH1N1 and H3N2 viruses. The mean and standard error (SEM) is presented in each time point. The arrows below D0 and D28 indicate challenge of the pigs with pH1N1 and immunization with ChAdOx2-NPM1-NA, respectively. Significant statistical differences are listed in Table 1. 


\section{Figure 2}

a
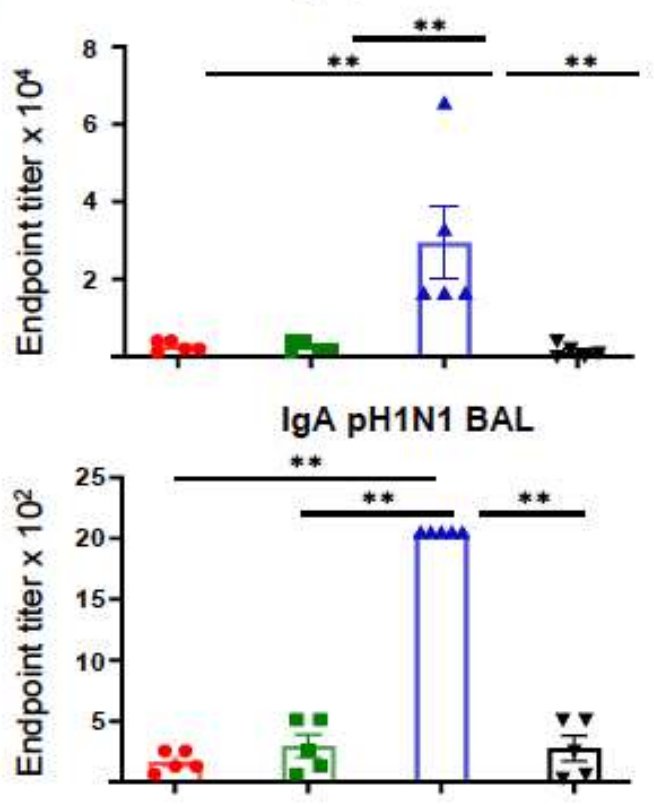

IgA pH1N1 nasal swabs

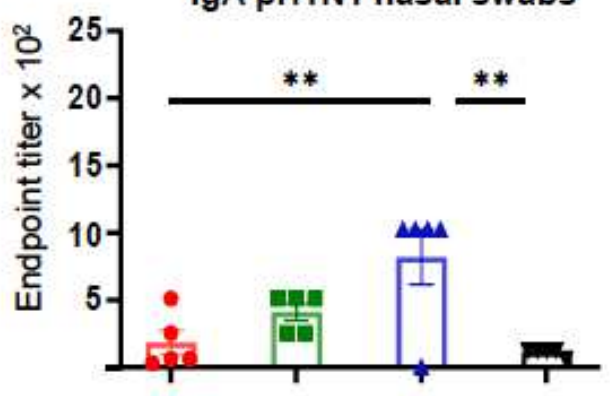

b

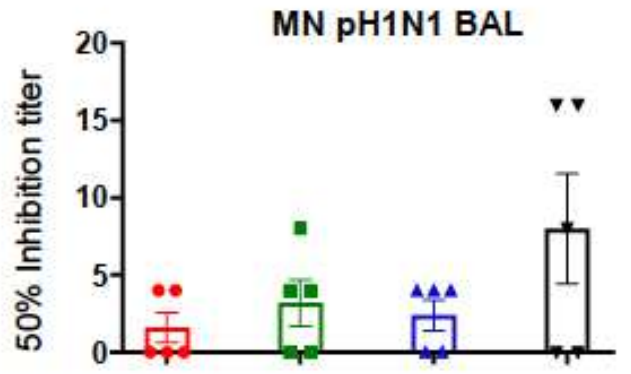

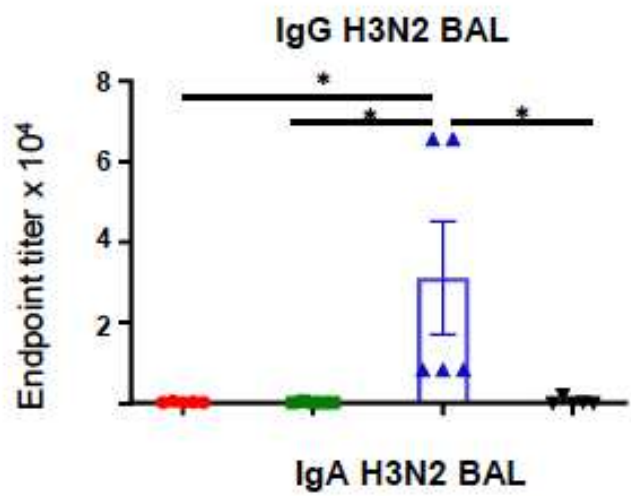
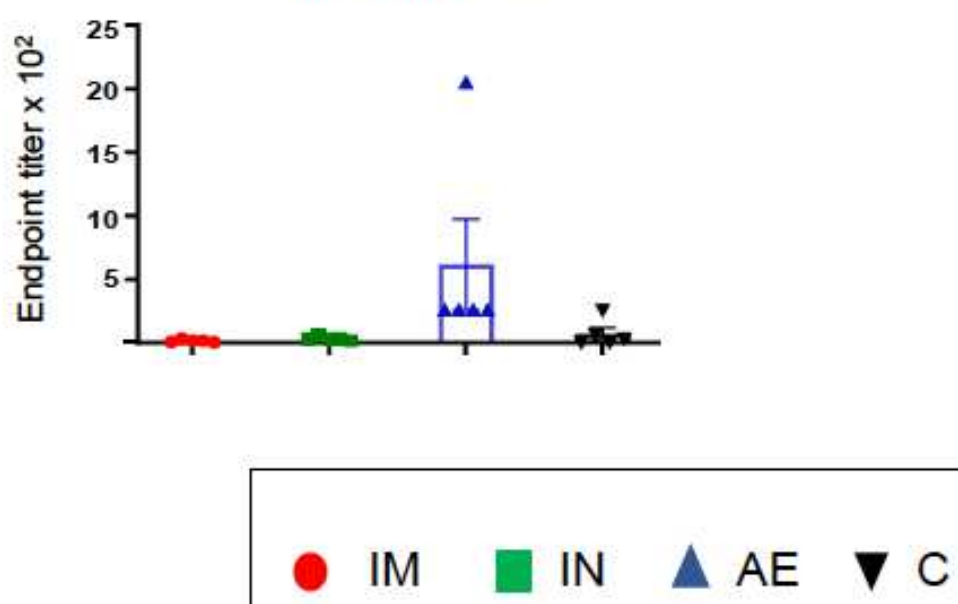

MN H3N2 BAL

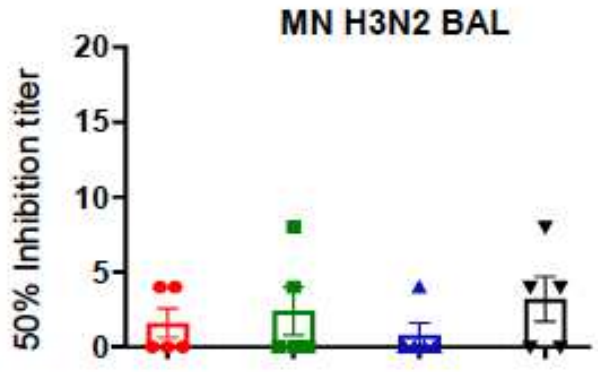

Figure 2

Mucosal antibody responses. a pH1N1 and H3N2 specific IgG and IgA responses in BAL, and pH1N1 specific IgA responses in nasal swabs, were determined by ELISA 4 weeks after immunization. b BAL neutralizing titers were determined by microneutralization (MN) of pH1 1 1 and $\mathrm{H} 3 \mathrm{~N} 2$ four weeks after immunization. The top of each bar indicates the mean and the line the SEM. Each symbol (circle, square 
and triangles) represents one animal. Asterisks denote significance between indicated groups $\left({ }^{*} p<0.05\right.$ and $\left.{ }^{*} \mathrm{p}<0.01\right)$ and were analyzed by one-way ANOVA and Bonferroni's multiple comparisons test.

\section{Figure 3}

a

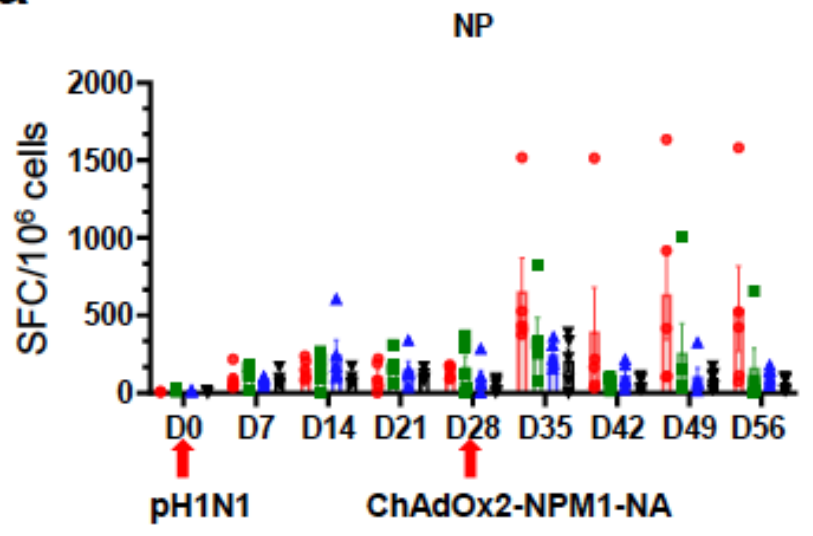

M1

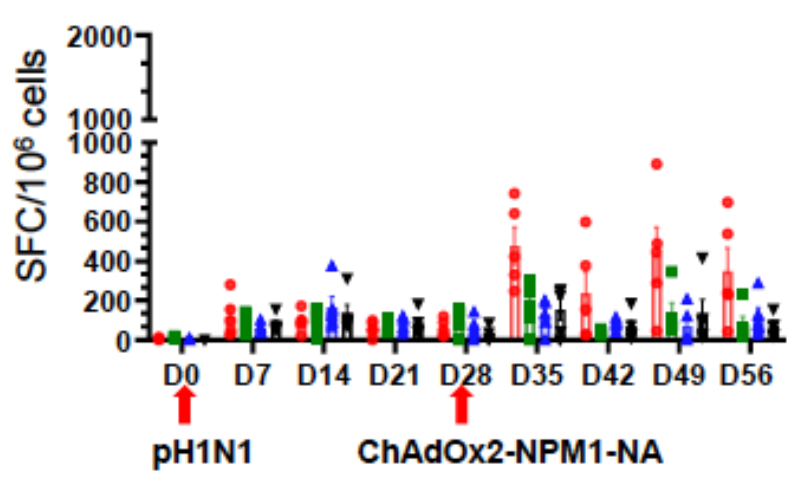

b

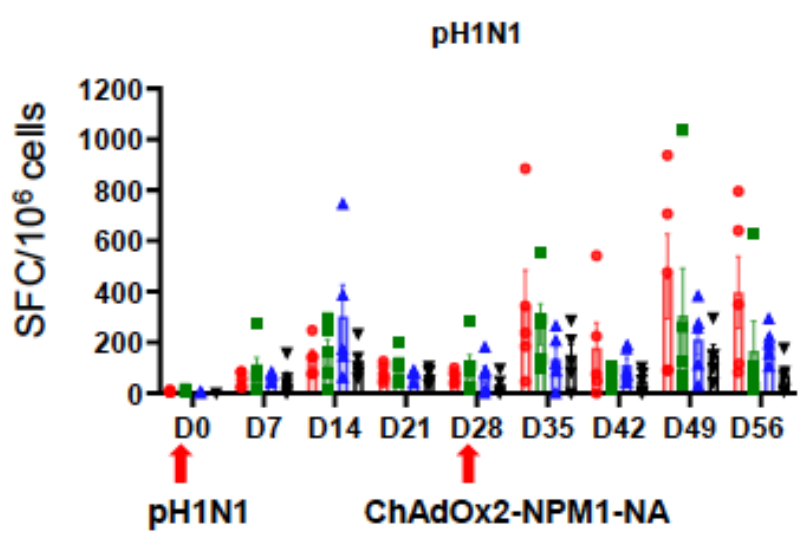

NA
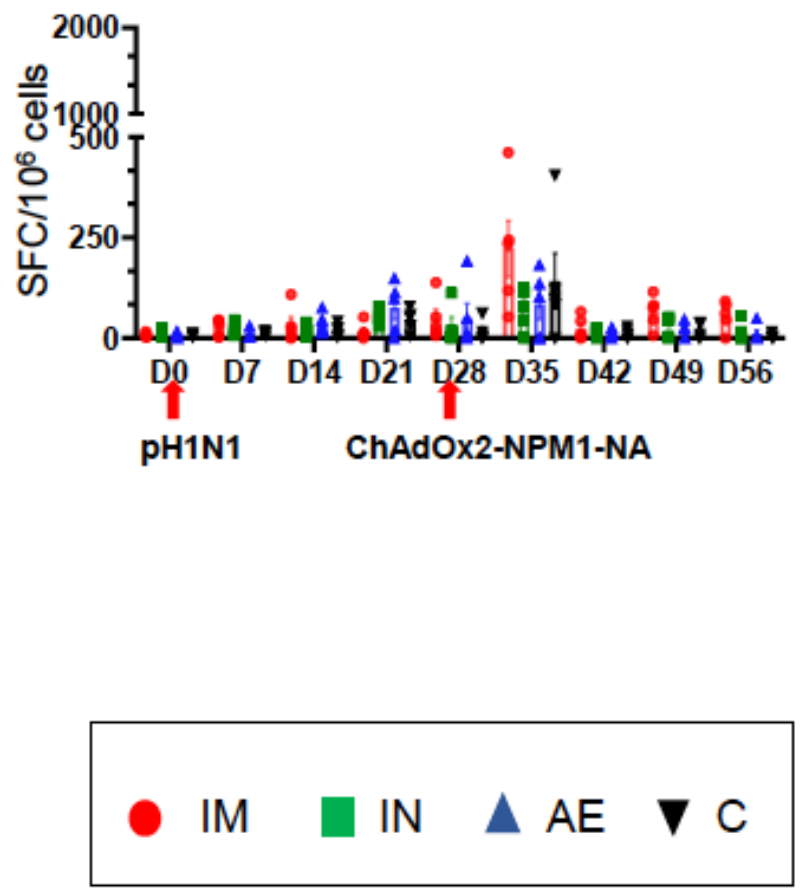

H3N2

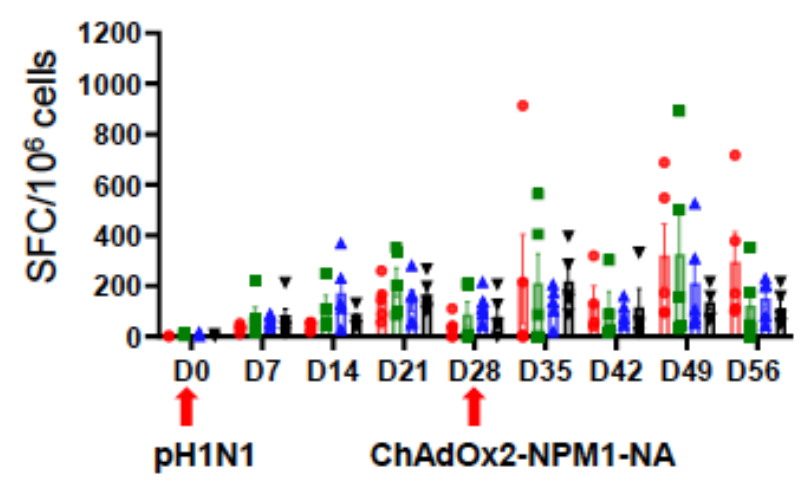

Figure 3

IFNY ELISpot responses in PBMC. IFNy secreting spot forming cells (SFC) were enumerated during the time course following stimulation with a a pool of peptides covering NP, M1 and NA proteins or b pH1N1 and H3N2 viruses. The arrows below D0 and D28 indicate the challenge of the pigs with pH1N1 and the 
immunization with ChAdOx2-NPM1- NA, respectively. The C group was not immunized. Each symbol represents an individual animal, the top of the bar the mean and the line the standard error (SEM). Significant statistical differences are listed in Table 1.

\section{Figure 4}

a
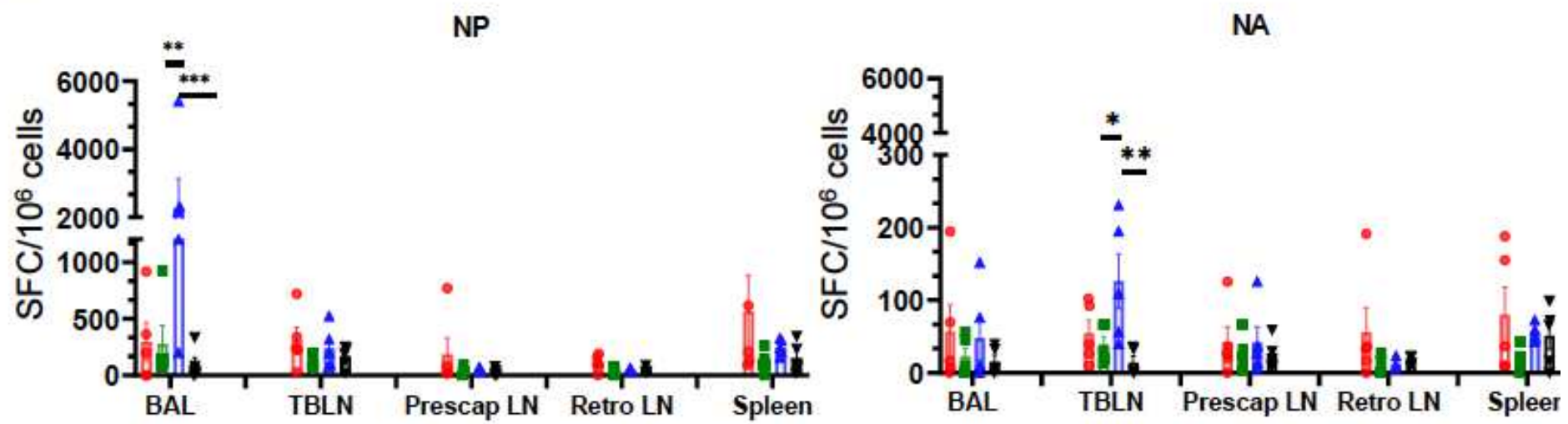

M1
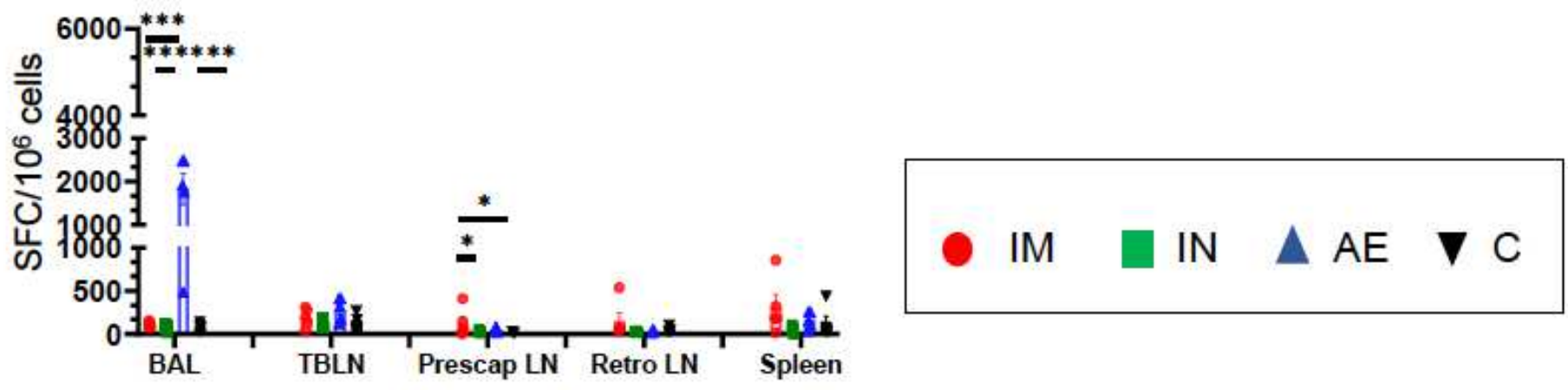

b
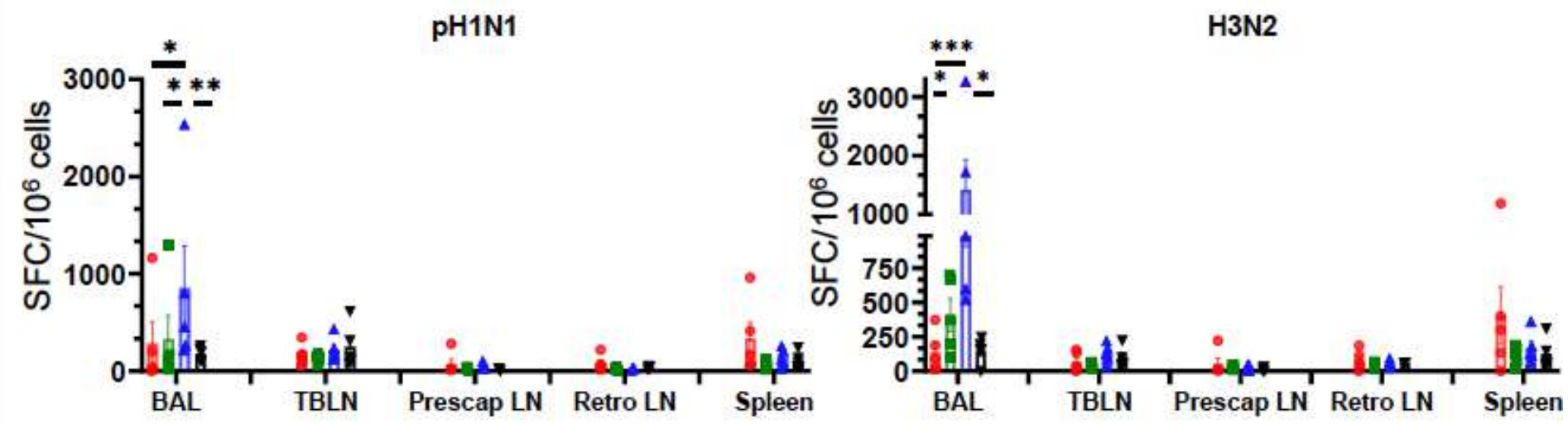

Figure 4

IFNy ELISpot responses in tissues. IFNy secreting spot forming cells (SFC) were enumerated in BAL, tracheobronchial lymph nodes (TBLN), prescapular lymph nodes (prescap LN) retropharyngeal lymph 
nodes (retro LN) and spleen on D56. Cells from tissues were stimulated with a pool of peptides covering $\mathrm{NP}, \mathrm{M} 1$ and NA proteins or $\mathrm{b} \mathrm{pH} 1 \mathrm{~N} 1$ and $\mathrm{H} 3 \mathrm{~N} 2$ viruses. Each symbol represents an individual animal, the top of the bar the mean and the line the standard error (SEM). Asterisks denote significance between indicated groups $\left({ }^{\star} p<0.05,{ }^{*} p<0.01,{ }^{* *} \mathrm{p}<0.001\right)$ and were analyzed by two-way ANOVA and the Bonferroni multiple comparisons test.

\section{Figure 5}
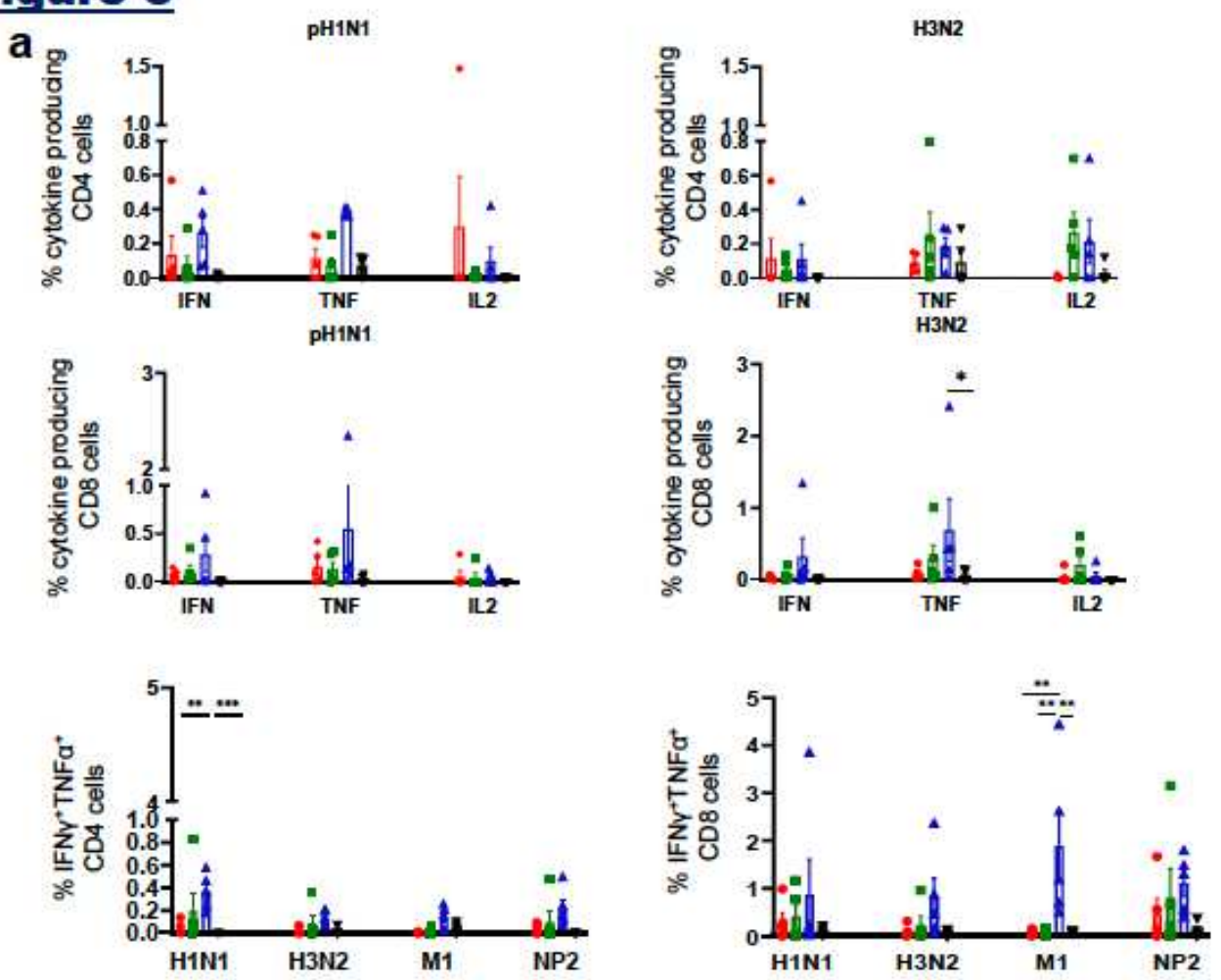

b
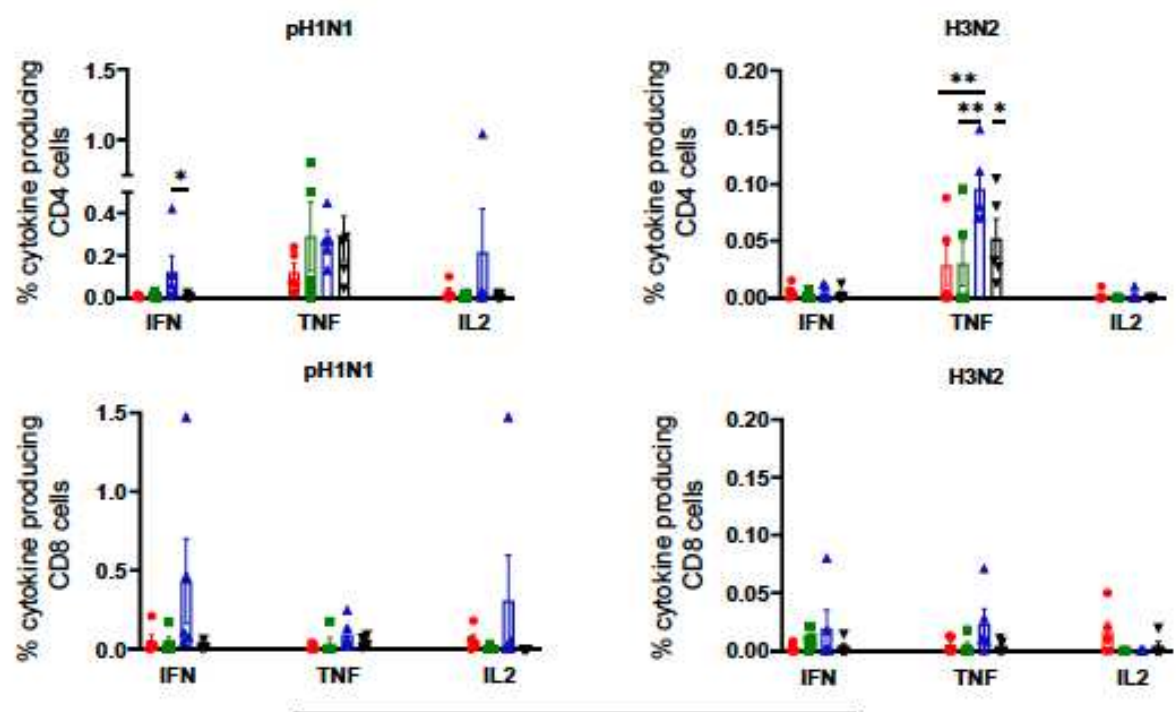

\section{$\mathrm{IM} \quad \mathrm{IN} \boldsymbol{\mathrm { A }} \mathrm{AE} \boldsymbol{\mathrm { V }}$}

Figure 5 
T cell cytokine responses in BAL and TBLN a BAL and b TBLN were collected four weeks post immunization Cryopreserved cells were thawed, stimulated with pH1N1 or H3N2 and IFNy, IL-2,TNF and IFNYTNF cytokine secretion was measured in CD4 and CD8 T cells by intracellular cytokine staining IFNYTNF co production within CD4 and CD8 T cells in BAL was determined following M1 and NP2 protein stimulation Each symbol represents an individual animal, the top of the bar the mean and the line the standard e rror ( Two Way ANOVA and Bonferroni's multiple c omparisons test were used to compare responses between groups and asterisks indicate significant differences $\left({ }^{*} p<0.05,{ }^{* *} p<0.01{ }^{* \star *} p<0.001\right)$.

\section{Figure 6}

a
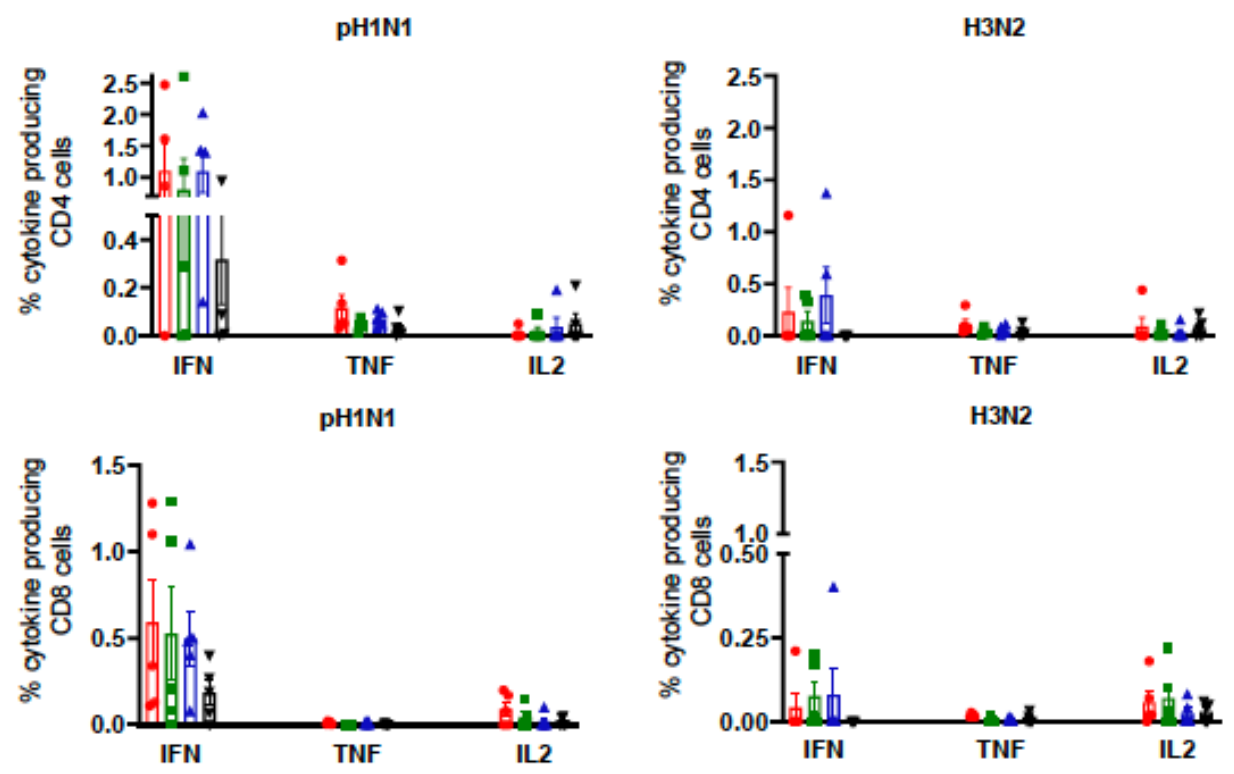

b
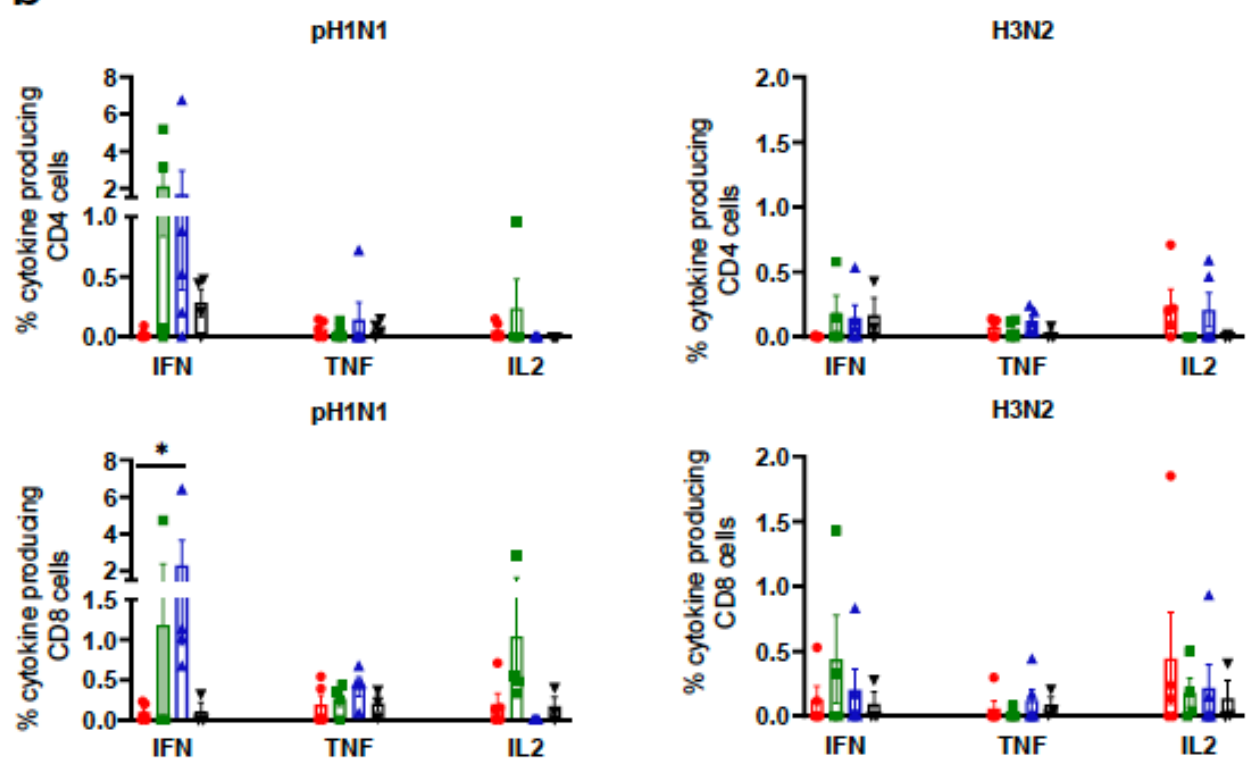

\section{- IM $\square \mathrm{IN} \Delta \mathrm{AE} \quad \boldsymbol{V} \mathrm{C}$}




\section{Figure 6}

T cell cytokine responses in spleen and nasal turbinates a Spleen and b nasal turbinates were collected at four weeks post immunization Cryopreserved cells were thawed, stimulated with pH1N1 or H3N2 and IFNy, TNF and IL-2-cytokine secretion was measured in CD4 and CD8 T cells by intracellular cytokine staining Each symbol represents an individual animal, the top of the bar the mean and the line the standard error mean ( Two Way ANOVA and Bonferroni multiple comparisons tests were used to compare responses between groups and asterisks indicate significant differences $\left({ }^{\star} \mathrm{p}<0.05\right)$.

\section{Supplementary Files}

This is a list of supplementary files associated with this preprint. Click to download.

- Supplementaryinformation.pdf 